\title{
Disciplina escolar Ciências: inovações curriculares nos anos de 1950-1970
}

\section{Science teaching: curriculum innovations in the years 1950-1970}

\author{
Daniela Fabrini Valla ${ }^{1}$. Diego Amoroso Gonzalez Roquette ${ }^{2}$ • \\ Maria Margarida Gomes ${ }^{3}$. Marcia Serra Ferreira ${ }^{4}$
}

\begin{abstract}
Resumo: O trabalho analisa aspectos produtores de significados curriculares para a disciplina escolar Ciências durante as décadas de 1950/70: as políticas internacionais e nacionais que influenciaram a educação brasileira; as mudanças curriculares que marcaram a disciplina no âmbito de um 'movimento renovador'; as ações curriculares expressas em livros didáticos. Com base em estudos sócio-históricos no campo do Currículo e, particularmente, sobre as disciplinas escolares, compreendemos as 'inovações' como construções que resultam de tensões entre o tradicional e o 'novo'. Nessa perspectiva, defendemos que a introdução de conhecimentos ecológicos, nos anos de 1970, na disciplina escolar Ciências, pode ser considerada uma 'inovação' curricular que dialoga com 'tradições' já existentes. Tomando os livros didáticos como materiais curriculares que participam das 'invenções de tradição', percebemos as coleções de Paulo Maurício Silva e Sebastião Rodrigues Fontinha Filho, publicadas no período, trazendo esses conhecimentos ecológicos em meio às influências sofridas pelos padrões e retóricas hegemônicos.
\end{abstract}

Palavras-chave: Ensino de Ciências. Currículo. História das Disciplinas. Ecologia.

Abstract: The paper examines aspects related to curriculum meanings produced in the school Science subject from the 1950's to the 1970's: (i) national and international policies that influenced Brazilian education, (ii) curriculum changes that occurred in a context of a 'renewal movement', and (iii) curricular activities expressed in textbooks. Based on socio-historical studies in the field of curriculum and particularly on school subjects, we understand 'innovations' as resulting from tensions between what is traditional and what is 'new'. From this perspective, we argue that the introduction of ecological contents in school science during the 1970's was a curriculum 'innovation' that dialogues with already existing 'traditions'. Considering textbooks as part of 'tradition inventions', we conclude that the curriculum materials of Paulo Maurício Silva and Sebastião Rodrigues Fontinha Filho show the ecological contents as influences of hegemonic patterns.

Keywords: Science teaching. Curriculum. History of School Subjects. Ecology.

${ }^{1,2,3,4}$ Programa de Pós-Graduação em Educação, Universidade Federal do Rio de Janeiro (UFRJ), Avenida Pasteur, 250, fundos, Praia Vermelha, CEP: 22290-240, Rio de Janeiro, RJ, Brasil. E-mail:

danifabrini@gmail.com 


\section{Introdução}

Neste trabalho, apresentamos uma análise de natureza sócio-histórica acerca de três aspectos produtores de significados para os currículos da disciplina escolar Ciências: o primeiro refere-se às políticas internacionais e nacionais que influenciaram a educação brasileira durante as décadas de 1950/70; o segundo diz respeito às significativas mudanças curriculares que marcaram essa disciplina escolar no período; e o terceiro concentra-se em ações curriculares do ensino dessa disciplina expressas em materiais didáticos e em depoimento de um profissional. O trabalho foi produzido no âmbito de pesquisas que vimos realizando no campo do Currículo, com o objetivo de analisar iniciativas curriculares inovadoras ocorridas no ensino de Ciências e na formação de professores no Estado do Rio de Janeiro ${ }^{5}$. Especificamente, neste artigo, focalizamos o período do 'movimento de renovação do ensino de Ciências', o qual influenciou fortemente os rumos da disciplina escolar Ciências.

Tomando como referência os estudos de Goodson (1995, 1997), Ferreira (2005, 2007), Gomes (2008) e Gomes, Selles e Lopes (2013), analisamos os rumos sócio-históricos dessa disciplina escolar considerando tanto os acontecimentos internacionais e nacionais do período quanto a constituição da mesma em meio a finalidades de caráter 'acadêmico' - nas quais os conhecimentos selecionados possuem um valor em si mesmo, não sendo necessária a elaboração de nenhuma outra justificativa para ensiná-los -, de caráter 'utilitário' - isto é, que focalizam conhecimentos práticos e técnicos - e de caráter 'pedagógico', valorizando os conhecimentos pessoais, sociais e os do senso comum. Entendemos que tais finalidades são o resultado de ações e de movimentos sociais exercidos por grupos e subgrupos no interior das disciplinas escolares, que passam por significativas mudanças durante as suas histórias de inserção nos currículos, e os debates acerca delas podem ser analisados em termos de conflitos por status, recursos e território (GOODSON, 1995, 1997).

Para a análise das mudanças na evolução sócio-histórica da disciplina escolar Ciências, utilizamos um sentido de 'inovação' baseado nos trabalhos de Ferreira (2005, 2007) e Gomes (2008) que, utilizando os escritos de Goodson (1995, 1997) e Cordeiro (2002), buscam compreender os currículos dessa disciplina em meio a movimentos que tanto as aproximam quanto as afastam de iniciativas 'inovadoras'. Ferreira (2005, 2007), por exemplo, questiona análises dicotômicas que percebem certas disciplinas escolares estabilizadas em uma única condição: como 'tradicional/antiga' ou como 'moderna/renovada'. Concordando com a autora, entendemos que a inserção de uma nova temática e/ou metodologia nos currículos de Ciências pode ser considerada uma ação 'inovadora' que dialoga com tradições já existentes.

Concebemos as 'inovações' curriculares, portanto, como movimentos sociais que, no interior de disciplinas escolares específicas, originam arranjos semelhantes e, simultaneamente, diferenciados daqueles já existentes, redimensionando as finalidades educacionais das mesmas.

\footnotetext{
${ }^{5}$ Estamos nos referindo aos projetos de pesquisa: 'Conhecimentos ecológicos nas disciplinas escolares Ciências e Biologia: um estudo curricular sócio-histórico' (CNPq); 'Currículo de Ciências: entre histórias e políticas para a formação de professores' (CNPq), e 'Sentidos das relações entre teoria e prática em cursos de formação de professores em Ciências Biológicas: entre histórias e políticas de currículo’ (CNPq e FAPERJ). Ver, também, as dissertações de mestrado de Valla (2011) e Roquette (2011).
} 
Baseando-nos em Goodson (1997), consideramos que as diversas disciplinas escolares - o que inclui Ciências - constituem campos de disputas por reconhecimento, material e ideológico, estabelecido por instâncias internas e externas aos grupos sociais que delas participam. Percebendo que as disciplinas escolares são produzidas por esses grupos sociais que atuam e que fortalecem as mesmas, mas que também são limitados em suas ações pelos valores criados e divulgados por estruturas externas, concordamos com Goodson (1997) acerca da necessidade de uma convergência entre objetivos internos e externos para a ocorrência de mudanças mais fortemente 'visíveis'. Assim, compreendendo os currículos como construções sócio-históricas conflituosas que acontecem em meio a disputas internas por hegemonia, assim como por embates no campo educacional e social mais amplo, buscamos aprofundar nossas reflexões acerca do momento em que ocorreu o chamado 'movimento de renovação do ensino de Ciências' no país. Para tal, na próxima seção, apresentamos o momento político vivido pela educação brasileira no período.

\section{Compreendendo a situação política do período investigado}

Segundo Romanelli (2007), o governo de Juscelino Kubitschek, na segunda metade da década de 1950, embora continuasse apoiando a 'política de massas' da Era Vargas, optou por acelerar a expansão industrial, abrindo a economia brasileira ao capital estrangeiro. Com a implantação da indústria de base e, especialmente, com a instalação de grandes multinacionais, houve, no país, a criação de uma grande variedade de novos empregos. Além disso, o próprio Estado como impulsionador da expansão da economia nacional e da constituição de infraestruturas de comunicação, transportes e energia, criou muitas novas formas de ocupação. Houve, então, um processo de concentração do capital e do mercado que fez com que as possibilidades de ascensão da classe média passassem a ser dependentes de hierarquias ocupacionais que se ampliaram tanto no setor público quanto no setor privado. Consequentemente, a educação passou a ser o caminho provável da classe média para conquistar bons postos de trabalho. Nesse contexto, o sistema educacional apareceu como um provedor ainda insuficiente dos recursos humanos necessários em um momento com cada vez mais pressão por demanda social (ROMANELLI, 2007).

Romanelli (2007) destaca, então, que a política educacional pós-1964 visava, inicialmente, a atender as demandas quantitativas de educação, sem desconsiderar que tal expansão escolar também era vista como uma ameaça à ação desenvolvimentista do governo militar. Como o sistema educacional existente não conseguia responder nem ao sistema econômico vigente nem às demandas sociais por educação, foram adotadas medidas para resolver tal impasse. Afinal, de acordo com Romanelli (2007), o Estado precisava redefinir suas funções e se preparar tanto para combater a crise econômica quanto para voltar a expandir, e, nesse sentido, contava com investimentos externos. É daí que resultou a série de acordos de cooperação financeira e assistência técnica com a United States Agency for International Development (USAID), os quais, na área da Educação, foram feitos com o Ministério da Educação e Cultura (MEC) e ficaram conhecidos como Acordos MEC-USAID (ROMANELLI, 2007).

Internacionalmente, esses acordos da USAID e de outras agências estrangeiras - não só com o Brasil, mas com boa parte da América Latina - fizeram parte de uma estratégia de 
hegemonia norte-americana com os países considerados periféricos (FÁVERO, [19-]). Isso se explica pelo fato de, após a Segunda Guerra Mundial, o mundo se encontrar dividido em dois sistemas econômicos - Capitalismo e Socialismo - e estar sendo liderado por duas grandes potências em confronto: os Estados Unidos da América e a União Soviética. Nesse contexto, os ideais empresariais do 'american way of life' foram intervindo cada vez mais na educação brasileira (SANTOS; AZEVEDO, 2003), explicitando uma ação que, segundo Romanelli (2007, p. 210), "implicava doutrinação e treinamento de órgãos e pessoas intermediárias brasileiras, com vistas obviamente a uma intervenção na formulação de estratégias que [...] fossem adotadas pelos dirigentes, órgãos e instituições educacionais". O diretor do Office Education and Human Resources da USAID discorreu sobre a forma de atuação da agência, a qual:

Tem por função não a concepção de uma estratégia da educação, mas influenciar e facilitar esta estratégia nos setores nos quais seus conhecimentos, sua experiência e seus recursos financeiros podem ser uma força construtiva que ajudará a atingir os objetivos visados. Tal estratégia deve ser concebida essencialmente por aqueles que têm o poder de tomar decisões e disponham dos recursos necessários. É então aos dirigentes dos países em vias de desenvolvimento que cabe decidir sobre a estratégia da educação. (HILLARD, 1974 apud ROMANELLI, 2007, p. 210)

A educação passou, então, a ser vista como fator estratégico de uma política de desenvolvimento, um importante instrumento para conter conflitos sociais e eliminar obstáculos que impedissem o desenvolvimento econômico (ROMANELLI, 2007; FÁVERO, [19]. No contexto descrito, a USAID defendia que os problemas da educação no Brasil estavam na falta de recursos e na destinação dada aos mesmos, quando disponíveis, o que se refletia em um sistema de ensino considerado deficiente. Nesse sentido, suas propostas incluíam:

1. Estabelecer uma relação de eficácia entre recursos aplicados e produtividade do sistema escolar; 2. Atuar sobre o processo escolar em nível de microssistema, no sentido de se "melhorarem" conteúdos, métodos e técnicas de ensino; 3. Atuar diretamente sobre as instituições escolares, no sentido de conseguir delas uma função mais eficaz para o desenvolvimento; 4. Modernizar os meios de comunicação de massas, com vistas à melhoria da informação nos domínios da educação extra-escolar; 5. Reforçar o ensino superior, "com vista ao desenvolvimento nacional”. (ROMANELLI, 2007, p. 210)

Uma análise mais minuciosa de tais propostas reforça a ideia de que, apesar de a USAID estar, aparentemente, voltada apenas para a cooperação entre os dois países, fornecendo uma espécie de 'ajuda' externa, suas ações de intervenção, apoiadas pelas ações do governo militar, passaram a fornecer um conjunto de diretrizes políticas e técnicas para a reorientação do sistema educacional brasileiro, ampliando a presença do padrão de acumulação capitalista no Brasil (ROMANELLI, 2007). 
No que se refere às disciplinas escolares em Ciências, os acordos assinados com a USAID que nos interessam se referem, especialmente, às mudanças no então Ensino Médio ${ }^{6}$. Em 31 de março de 1965, por exemplo, foi assinado o Acordo MEC/CONTAP (Conselho de Cooperação Técnica da Aliança para o Progresso) - USAID para a melhoria desse ensino. De acordo com Romanelli (2007), esse acordo previa assessoria técnica estadunidense para o planejamento de ensino e para o treinamento de técnicos brasileiros nos Estados Unidos. Posteriormente, em 24 de junho de 1966, foi produzido o Acordo MEC/CONTAP-USAID de Assessoria para Expansão e Aperfeiçoamento do Quadro de Professores de Ensino Médio no Brasil, o qual previa, entre outros aspectos, a reformulação da formação inicial de professores no país (ROMANELLI, 2007). Já em 6 de janeiro de 1967 foi assinado o acordo MEC-SNEL (Sindicato Nacional dos Editores de Livros) - USAID de Cooperação para Publicações Técnicas, Científicas e Educacionais. Para Romanelli (2007), esse acordo tinha por objetivo produzir, no prazo de três anos, cinquenta e um milhões de livros para as escolas. Nesse caso, o MEC e o SNEL executariam o projeto, cabendo aos técnicos da USAID o exercício de todo o controle desde os detalhes técnicos de fabricação do livro até a ilustração, a editoração e a distribuição. Por fim, destacamos o Acordo MEC - USAID de 17 de janeiro de 1968, "criado para dar continuidade e complementar o primeiro acordo para desenvolvimento do Ensino Médio" (ROMANELLI, 2007, p. 213).

É nesse contexto que surgem investimentos específicos para o ensino de Ciências no país, fomentando ações que ficaram conhecidas no âmbito de um 'movimento renovador'. Assim, buscando compreender como importantes e interessantes 'inovações' curriculares puderam ser produzidas em meio a esse ideário conservador, na próxima seção, abordamos aspectos das disciplinas escolares em ciências relacionados a esses acordos MEC - USAID. Tratamos, especificamente, de questões que caracterizaram o 'movimento de renovação do ensino de Ciências' no Brasil, o qual foi influenciado por projetos curriculares estrangeiros e apostava, entre outros aspectos, na produção de um ensino de caráter mais prático e experimental.

\section{Situando as mudanças no ensino de Ciências no mesmo período}

No contexto político anteriormente descrito, caracterizado por conflitos em torno de concepções educacionais e de perspectivas de mudanças em nosso sistema de ensino, foram produzidas ações curriculares que ficaram conhecidas como parte de um 'movimento de renovação do ensino de Ciências' mais amplo. Iniciado após a Segunda Guerra Mundial, esse movimento ganhou força nas décadas aqui investigadas, isto é, os anos de 1950/60/70. Segundo Chassot (2004), ele foi fortemente influenciado pelas transformações ocorridas no ensino secundário estadunidense após o lançamento do satélite artificial Sputnik, em 1957, pela União Soviética. Na ocasião, em meio à Guerra Fria e sob a ameaça do expansionismo comunista - que se intensificou com a 'perda' da Corrida Espacial -, a educação científica passou a ser vista, nos Estados Unidos, como uma espécie de 'arma' que serviria para contro-

\footnotetext{
${ }^{6}$ Organizado em ginasial e colegial.
} 
lar as ambições de dominação dos soviéticos (RUDOLPH, 2006). Nesse momento, os Estados Unidos passaram a investir como nunca em seu sistema educacional, dando início a um período de reformas curriculares no ensino de Ciências que atingiram diversos países do bloco capitalista. Tais reformas, ainda que não tenham alcançado os resultados esperados frente ao montante de recursos investidos, foram produtoras de um movimento que efetivamente fomentou a elaboração de outros padrões para o ensino de Ciências, assim como para a formação de professores na área. Para Ferreira (2005, p. 160), esses padrões nos possibilitam "reconhecer e partilhar publicamente determinadas concepções acerca do bom e do mau professor de Ciências, e as certificações conferidas com base nesses padrões acabam tendo valor como moeda no mercado da identidade social (GOODSON, 1997, p. 27)".

Em nosso país, segundo Barra e Lorenz (1986), já por volta dos anos de 1950, os materiais aqui produzidos eram, sobretudo, livros-textos e material de apoio para atividades de laboratório. Tais materiais curriculares colocavam ênfase na adoção do método experimental nas salas de aula, visto que, muitas vezes, os alunos não desenvolviam atitudes vistas como científicas quando confrontados com problemas. Ainda em 1952, o Instituto Brasileiro de Educação, Ciência e Cultura (IBECC) produziu os primeiros kits destinados a alunos do nível Médio, incentivando-os a resolverem problemas por meio do método científico, de modo supostamente semelhante ao modo de pensar dos cientistas. Já em 1955, com mudanças na diretoria, o IBECC começou a receber subvenções da Fundação Rockefeller, que passou a apoiar a contínua produção de kits mais aperfeiçoados, voltados para alunos do primário e do secundário.

No ano de 1959, a Fundação Ford lançou o seu programa de assistência aos países da América Latina, tendo como principal objetivo a melhoria no ensino de Ciências. Nesse contexto, a instituição forneceu ao IBECC, no início da década de 1960, subvenções para a produção e para a distribuição de kits, para cursos direcionados ao treinamento de professores de Ciências e para a tradução, a adaptação e a publicação de materiais didáticos nessa área. Nesse contexto, o IBECC promoveu a tradução e a adaptação dos projetos curriculares estadunidenses conhecidos pelas siglas $\mathrm{BSCS}^{7}, \mathrm{CBA}^{8}, \mathrm{CHEMS}^{9}$ e $\mathrm{PSSC}^{10}$, entre outros. Como tais coleções não despertaram grande interesse dos editores brasileiros, o IBECC firmou um convênio com a Universidade de Brasília e, "com o apoio financeiro da Fundação Ford e a garantia da USAID” (BARRA; LORENZ, 1986, p. 1974), traduziu e adaptou, entre 1961 e 1964, esses materiais curriculares.

Segundo Barra e Lorenz (1986) e Chassot (2004), uma maior possibilidade de utilização direta ou indireta desses materiais estrangeiros em nossas escolas ocorreu, no início dos anos de 1960, com a promulgação da Lei 4.024/61, que dava mais liberdade às escolas nas escolhas curriculares (BRASIL, 1962). Afinal, para Ferreira (2005), a flexibilidade curricular dessa legislação também se expressou na ausência de programas de ensino a serem obrigatoriamente seguidos pelas diversas instituições escolares. Segundo Lorenz (2004), as reformas

\footnotetext{
${ }^{7}$ Biological Science Curriculum Study.

${ }^{8}$ Chemical Bond Approach.

${ }^{9}$ Chem Study.

${ }^{10}$ Physical Science Study Committee.
} 
curriculares estadunidenses pós-Sputnik foram embasadas em princípios pedagógicos relacionados a uma nova visão da natureza das ciências, do processo científico e de seu ensino, contando com o ideário de autores como Jerome Bruner e Joseph Schwab ${ }^{11}$. Bruner (1960) defendia a importância da estrutura das disciplinas de caráter científico como base para a sua teoria do ensino, com os princípios básicos de cada disciplina relacionados entre si e com fatos e conceitos a ela ligados. Assim, os conceitos científicos deveriam ser ensinados a partir da organização de suas inter-relações. A ênfase na estrutura das disciplinas científicas representava uma tentativa de rompimento com orientações curriculares ligadas ao princípio de 'educação para a vida' de John Dewey ${ }^{12}$, aspecto que, segundo Rudolph (2002), assumiu caminhos diferenciados do que propunha o ideário deweyano.

O outro nome ligado às reformas estadunidenses, Schwab (1962), defendia um ensino de Ciências que partisse de resultados de investigação, ao invés de ensinar conclusões prontas e acabadas. Para o autor, os estudantes deveriam aprender por meio de práticas escolares de investigação científica que possibilitassem a compreensão de conceitos. Assim, deveriam ser usados os métodos da 'redescoberta', ensinando os estudantes a fazerem perguntas, buscarem evidências e avaliarem os resultados de investigações. Tanto os trabalhos de Bruner como os de Schwab tinham forte relação com a compreensão da natureza dos conhecimentos científicos, a partir da qual eram propostas as estratégias para o ensino das disciplinas escolares (LORENZ, 2004). Ambos os autores, influenciados por campos científicos específicos, valorizavam a seleção e a estruturação dos conteúdos com vistas à organização dos currículos escolares, o que possuía relação direta com a própria estrutura interna de cada campo disciplinar. No ensino de Ciências brasileiro, a influência desses autores se deu em meio a outras, do campo educacional, e se voltou para os processos de planejamento, os quais deveriam se basear nas etapas de desenvolvimento dos alunos.

Com investimentos estrangeiros fomentados pelo momento político e educacional brasileiro, esses princípios pedagógicos das reformas curriculares estadunidenses guiaram a produção de materiais didáticos no Brasil. Nesse contexto, além do IBECC, outras instituições participaram ativamente do 'movimento renovador' entre os anos de 1950/70, tais como a Fundação Brasileira para o Desenvolvimento do Ensino de Ciências (FUNBEC) e os Centros de Ciências. Criados em 1963 pelo Ministério da Educação e Cultura, a partir de convênios com universidades e secretarias de educação, os seis Centros de Ciências foram articuladores de projetos idealizadores de materiais didáticos e de ações voltadas para a atualização docente (BARRA; LORENZ, 1986; FERREIRA, 2005; KRASILCHIK, 1995).

Segundo Valla e Ferreira (2012), uma dessas instituições, o Centro de Ciências do antigo Estado da Guanabara (CECIGUA), teve grande importância na formação de gerações de professores que passaram a atuar nas escolas do estado. A partir das ações desenvolvidas pelos professores Ayrton Gonçalves da Silva e Newton Dias dos Santos, os quais par-

\footnotetext{
${ }^{11}$ Lorenz (2004), com base em DeBoer (1991), destaca as seguintes obras destes autores: BRUNER, J. The process of education. New York: Vintage, 1960; SCHWAB, J. The teaching of science as inquiry. In: The teaching of science. Cambridge: Harvard University Press, 1962. p. 1-103.

${ }^{12}$ Rudolph (2002) se refere, em especial, ao livro: DEWEY, J. Democracy and education. New York: Macmillan, 1916.
} 
ticiparam da fundação e da gestão inicial do CECIGUA, as autoras mostram como foram produzidas 'inovações' no ensino de Ciências nessa instituição em meio ao movimento mais amplo. Ainda para Valla e Ferreira (2012), a disseminação das diversas produções dessa instituição junto aos professores do então Estado da Guanabara tornou-a uma poderosa agência de divulgação de modelos de ensino inserida em uma perspectiva internacional de mudança para o ensino das Ciências, muito embora seus principais protagonistas tenham deixado marcas específicas nas produções cariocas. Nessa perspectiva, podemos compreender o CECIGUA como uma:

Instituição social marcada pelas concepções e pelas ações de seus principais protagonistas [...], assim como a sua atuação como uma agência social a produzir retóricas e a fornecer certificações que acabaram tendo crescente valor como moeda no mercado da identidade social (GOODSON, 1997, p. 27) dos professores de Ciências e Biologia. (VALLA; FERREIRA, 2012, p. 181)

Apoiadas em Goodson (1997), Valla e Ferreira (2012) argumentam que o CEGIGUA contribuiu fortemente para a construção de padrões socialmente legítimos de professores, alunos, temas e atividades de ensino, os quais foram sendo apropriados por grupos das disciplinas escolares em Ciências. Na próxima seção, exemplificamos esse processo por meio da análise de aspectos relacionados a uma coleção de livros didáticos produzida nos anos de 1970 sob a influência dos referidos padrões sociais - os quais possibilitaram a obtenção de apoio ideológico e material para a publicação e a disseminação dos mesmos -, ainda que trazendo outras 'inovações' curriculares.

\section{Analisando a ecologia como 'inovação' curricular em materiais didáticos do período}

No campo educacional, a noção de 'inovação' curricular por vezes se confunde com significados que levam a uma contraposição entre o ‘novo' e o ‘velho'. Nesse movimento, o que é entendido como 'velho' se associa ao 'tradicional' e deve ser superado, sendo substituído pela 'novidade' curricular. Segundo Cordeiro (2002), por exemplo, a educação na modernidade vem se caracterizando por uma busca pelas 'inovações' como uma forma de superação de modelos educacionais com resultados insatisfatórios. Além disso, durante as décadas de 1970 e 1980, no Brasil, havia uma grande produção nos meios educacionais em que "predominava a aposta de mudança da sociedade e no potencial formador e transformador da escola e do ensino" (CORDEIRO, 2002, p. 39). Essa aposta na mudança como uma característica desse período é particularmente interessante no que diz respeito à presença de conteúdos ecológicos em materiais escolares destinados à disciplina escolar Ciências. Afinal, esta passava por transformações advindas de mudanças nacionais e internacionais nas visões de seu ensino e sofria, ainda, influências de movimentos em prol de uma educação voltada para o meio ambiente. Para o autor, no entanto, 'inovações' como essa no campo educacional não surgem "como rupturas bruscas, mas como resultado de tensões entre as novas formas e as antigas ao 
longo de períodos bastante extensos" (CORDEIRO, 2002, p. 40). Nessa mesma direção, de acordo com Ferreira (2007, p. 140), as disciplinas escolares devem ser compreendidas:

Em meio a movimentos que ora se aproximam e ora se afastam das iniciativas inovadoras, e não como uma "entidade monolítica" - para usar uma expressão de Goodson (1995, p. 120) - que somente pode ser percebida de forma dicotômica, ou seja, como tradicional/antiga ou como moderna/renovada.

Nessa perspectiva, defendemos que a introdução de temáticas ecológicas nos anos de 1970, em um contexto sócio-histórico de fortalecimento da disciplina escolar Ciências, pode ser considerada uma 'inovação' curricular que dialoga com 'tradições' já existentes. Assim, concebemos a 'inovação' como um movimento social que, no interior dessa disciplina escolar, origina outros elementos a partir daqueles já presentes nos currículos do Ensino Fundamental, transformando-os e sendo transformado por eles, tendo como resultado uma construção que apresenta novas finalidades educacionais. Nesse sentido, percebemos que a disciplina escolar Ciências, com sua história e suas 'tradições' curriculares, representa o 'substrato' no qual se deu a incorporação dos conhecimentos ecológicos, que foram ressignificados como conteúdos de ensino. Um exemplo disso pode ser evidenciado no trabalho de Gomes (2008) ao analisar materiais didáticos produzidos no período em questão. Esta autora, investigando os referidos conhecimentos em livros didáticos da disciplina escolar Ciências, no período compreendido entre as décadas de 1930 e 2000, buscou compreender esses conhecimentos escolares em perspectiva sócio-histórica, relacionando-os a uma diversidade de aspectos que vêm caracterizando o seu ensino. Tais aspectos podem ser reconhecidos por meio dos seguintes 'enfoques curriculares', presentes em materiais didáticos produzidos para a disciplina escolar Ciências: 'história natural', 'ecologia', 'anatomia, fisiologia e saúde humanas', 'ciência e experimentação', 'ciência e tecnologia' e 'vida cotidiana'. Os enfoques são definidos pela autora como representando:

Os fios condutores da seleção, distribuição e organização dos conteúdos de ensino assumidos pelos autores. Incluem-se tanto as proposições para o ensino das Ciências expressas nos textos de apresentação aos professores e estudantes, quanto sua expressão na produção dos conteúdos de ensino. Nos livros didáticos, é possível identificar e analisar os enfoques organizadores do currículo que vêm fazendo parte da história do ensino de Ciências no Brasil. (GOMES; SELLES; LOPES, 2013, p. 483)

Esses 'enfoques curriculares' podem ser interpretados como formas de evolução do currículo que, de acordo com Goodson $(1995,1997)$, são conflituosas e disputam status e território no âmbito das comunidades disciplinares e nos processos de escolarização mais amplos. Em outras palavras, tais enfoques representam tradições curriculares em disputa no ensino de Ciências desde a década de 1930. Por exemplo, a marca do enfoque 'ciência e 
experimentação’ pode ser vista como uma tradição que, em diferentes momentos do período em questão, se expressa com características distintas, sempre interagindo com outros enfoques curriculares também valorizados na disciplina escolar. Gomes (2008) destaca que os materiais publicados a partir de 1960 revelam, na organização e distribuição de conteúdos, aspectos que destacam tanto a metodologia da produção dos conhecimentos científicos quanto os contextos a eles relacionados. Nesse período, as perspectivas utilitárias e pedagógicas foram fortemente valorizadas, mas se manifestaram a partir de composições com tradições mais acadêmicas produzidas durante o 'movimento de renovação do ensino das Ciências', cujas marcas podem ser percebidas nos materiais didáticos brasileiros até os dias de hoje. Assim, é possível afirmar que, a partir do referido movimento, os materiais didáticos valorizavam o método científico experimental como uma estratégia pedagógica no ensino de Ciências. No entanto, tal valorização não impossibilitou a inserção de outros enfoques, tais como o da 'ecologia'.

Podemos dizer, então, que o surgimento de algo diferente do já existente não se dá pelo apagamento deste, mas por um processo de construção curricular no qual se 'inventam' tradições que, no sentido proposto por Hobsbawm (2002, p. 9), refere-se a:

Um conjunto de práticas, normalmente reguladas por regras tácitas ou abertamente aceitas; tais práticas, de natureza ritual ou simbólica, visam inculcar certos valores e normas de comportamento através da repetição, o que implica, automaticamente, uma continuidade em relação ao passado. Aliás, sempre que possível, tenta-se estabelecer continuidade com um passado histórico apropriado.

Compreendendo os livros didáticos como materiais curriculares que, em nossa sociedade, guardam 'indícios' de todo esse processo de 'invenção de tradição', tomamos as coleções de Paulo Maurício Silva e Sebastião Rodrigues Fontinha Filho, publicadas no período, para investigar a introdução de conhecimentos ecológicos na disciplina escolar Ciências. De acordo com Gomes (2008), os referidos autores começaram a publicar livros didáticos de Ciências no início da década de 1970 e se mantiveram no mercado editorial até a década de 1990. Esses autores fizeram parte do ensino de Ciências de muitas escolas cariocas, incluindo o Colégio Pedro II, no qual suas obras chegaram a ser adotadas em paralelo aos livros de Oswaldo Frota-Pessoa, durante os anos de 1980 (FERREIRA, 2005). Além disso, as primeiras coleções desses autores, editadas nos anos de 1970, circularam pelas escolas juntamente com coleções fortemente ligadas ao 'movimento de renovação do ensino de Ciências'. Tal fato sugere que Paulo Maurício Silva e Sebastião Rodrigues Fontinha Filho influenciaram e foram influenciados por tal movimento, uma vez que suas coleções didáticas disputaram o território e a hegemonia da disciplina escolar Ciências nesse período.

Formado no curso de História Natural da Faculdade Nacional de Filosofia da Universidade do Brasil, o professor Sebastião Rodrigues Fontinha Filho acompanhou todo o percurso do 'movimento renovador' como amigo do filho do professor Ayrton Gonçalves da Silva - um dos protagonistas desse movimento no então Estado da Guanabara (FERREIRA, 2005, 2007; VALLA, 2011; VALLA; FERREIRA, 2012) - e frequentando o CECIGUA como professor recém-formado. Quando indagado sobre o seu envolvimento com essa instituição, ele declarou: 
Era obrigatório. Quem não passava pelo CECIGUA estava 'morto'. Sábado a gente ia lá para comprar [...] ácido sulfúrico, mais não sei o quê,, para fazer experiências e tinha sempre um 'papinho', uma 'patotinha' que se encontrava. [...] Hoje a gente entrava como aluno, amanhã entrava como instrutor. [...] Todo mundo era competente. Tinha umas pessoas assim fora de série [como], por exemplo, [o] Cândido Oromar [Figueiredo Vieira], de Física. [O] Cândido era genial. ${ }^{132}$

Durante as atividades das quais participou no CECIGUA, o professor Sebastião Rodrigues Fontinha Filho conheceu o professor Oswaldo Frota-Pessoa e se aproximou do professor Ayrton Gonçalves da Silva, dois importantes protagonistas do movimento renovador carioca. Sobre o segundo, ele teceu muitos elogios, demonstrando ter pelo trabalho do mesmo uma admiração profunda. Tal manifestação de carinho, no entanto, veio também acompanhada de comentários sobre o que o diferenciava do mestre:

Aquela história de física é física, água é água. [...] Eu dizia para o Ayrton: Ayrton a tua água vem de torneira, a tua água começa da torneira, abre a torneira aparece água. Quer dizer, lá em cima na atmosfera não tem, no solo não tem, quer dizer, como é a nossa visão de água? É a água dos seres vivos. O que nós fizemos? Nós fundimos o livro antigo "água, ar e solo", não é? Todos eles repetiam isso, e colocamos o seguinte: os seres vivos aqui dentro. Água, o berço da vida. A bistória em quadrinhos, os bichinhos. ${ }^{13}$

Foi dessa forma que, em entrevista realizada, o professor Sebastião Rodrigues Fontinha Filho expressou as suas ideias sobre um ensino de Ciências mais contextualizado e integrado por meio de uma visão mais ecológica dos fenômenos do planeta. Segundo ele, seus primeiros livros didáticos de Ciências, produzidos em parceria com o professor Paulo Maurício Silva, foram pioneiros na apresentação da ecologia como um enfoque organizador do currículo. O professor afirmou que, entre outras influências, essa visão ecológica teve origem em suas experiências de trabalho de campo orientadas por Segadas Vianna, professor do curso de História Natural da Faculdade Nacional de Filosofia da Universidade do Brasil. Vale ressaltar que Segadas Vianna foi revisor de uma das primeiras adaptações de importante material do movimento renovador, a 'Versão Verde' do BSCS, intitulada "Manual de biologia: exercícios de ecologia", que foi produzida pelo professor Oswaldo Frota-Pessoa e pela professora Myriam Krasilchik. Todas essas relações certamente indicam-nos quanto as ações voltadas para o ensino de Ciências, mesmo aquelas voltadas para o mercado editorial, dialogavam com o ideário e com os protagonistas do movimento renovador.

Foi, portanto, em um contexto educacional marcado pelo 'movimento de renovação do ensino de Ciências’ que Paulo Maurício Silva e Sebastião Rodrigues Fontinha Filho introduziram a ecologia como uma novidade nos seus livros didáticos. Essa temática, segundo Go-

\footnotetext{
${ }^{13}$ Entrevista com o professor Sebastião Rodrigues Fontinha Filho, realizada pela terceira autora deste texto em 15 de junho de 2007, no âmbito de seu doutoramento (GOMES, 2008).
} 
mes (2008), passa a fazer parte de um arcabouço comum de conteúdos de ensino que compõem os livros didáticos de Ciências a partir dos anos de 1970, constituindo um padrão de estabilidade e dando-nos a impressão de que tais conteúdos de ensino sempre estiveram presentes na disciplina escolar. A estabilidade curricular, no entanto, pode ser promovida pelas mudanças, como indicam os livros didáticos que apresentam a ecologia entre os enfoques que organizam o currículo. Nesses materiais, a ecologia se estrutura no interior de um conjunto de enfoques curriculares já existentes nos currículos da disciplina escolar Ciências até os anos de 1970. Assim, a entrada da ecologia se dá sem uma ruptura com as finalidades de ensino já existentes. Ao contrário, esse enfoque entra em consonância com as finalidades educacionais e a organização geral já estabelecidas sócio-historicamente, sendo firmemente ancoradas em uma concepção de integração referenciada em diversos campos científicos, mas apontando, também, para uma integração que é produzida com o cotidiano. Além disso, a ideia de integração na disciplina escolar Ciências é fortalecida por princípios pedagógicos do campo educacional produzidos em diferentes momentos históricos (GOMES, 2008).

Ainda segundo Gomes (2008), nesse novo enfoque, o que prevalece nos livros didáticos é a ecologia de ecossistemas ${ }^{14}$, isto porque a mesma atende mais apropriadamente às finalidades educacionais voltadas para a noção de integração curricular. Nesse sentido, os conteúdos relacionados a transferências de matéria e energia nos seres vivos e nos ambientes naturais são associados a outros conteúdos de ensino, ligando-os e contextualizando-os de diversas maneiras. Assim, em uma mescla de perspectivas acadêmicas, pedagógicas e utilitárias, os seres vivos são interligados a partir das relações que estabelecem uns com os outros no meio ambiente em que vivem. Em lógica semelhante, o corpo humano é relacionado a questões culturais e/ou ambientais, por intermédio das quais são apresentados conteúdos de ensino relacionados à saúde e/ou à qualidade de vida. A ecologia pode ainda ser apropriada para integrar os componentes principais do planeta Terra, indicando como tudo está interligado, inclusive a própria vida dos seres humanos.

Transformada por finalidades oriundas do campo pedagógico, a ecologia dos ecossistemas aparece nos livros didáticos de Ciências associada, também, a ideias de equilíbrio e desequilíbrio que acabam por ser relacionadas a princípios de harmonia e compreensão da vida e de sua preservação de uma forma global (GOMES, 2008). Com essa perspectiva, a ecologia dos ecossistemas se conjuga bem com explicações sobre como inserir o ser humano no conjunto dos seres vivos e nos ambientes naturais, assim como nas relações entre professores e estudantes em contextos de métodos ativos nas aulas de Ciências. Há, ainda, as inserções de finalidades que oscilam entre perspectivas utilitárias e pedagógicas mais ligadas às problemáticas ambientais, tais como as diversas abordagens a respeito dos recursos vivos e não vivos do planeta Terra. De acordo com Gomes (2008), a ecologia de ecossistemas -

\footnotetext{
${ }^{14}$ Ao longo da história de delimitação do campo científico da Ecologia, sua consolidação se deu em torno de dois paradigmas: um ligado à ecologia dos ecossistemas, considerando suas relações de transferência de energia e matéria; e o outro à ecologia das populações e comunidades, tendo como enfoque principal os organismos. Basicamente, o que diferencia os dois paradigmas são trabalhos científicos desenvolvidos em níveis diferentes de organização dos estudos sobre os seres vivos e suas inter-relações. Diferentemente da ecologia de populações, que aborda fenômenos que ocorrem no nível das relações entre indivíduos e populações, a ecologia dos ecossistemas trata de fenômenos relativos a grandes conjuntos de organismos (VIEIRA, 2003).
} 
como conhecimento acadêmico - vem sendo, assim, mais facilmente apropriada no âmbito escolar por atender à seguinte finalidade: a de confirmar e favorecer o caráter integrado da disciplina escolar Ciências. Em outras palavras, a ecologia dos ecossistemas do campo acadêmico da Biologia, associada a perspectivas de movimentos ambientais e de movimentos pedagógicos, representa uma mudança que ajuda a fortalecer a integração como princípio organizador da disciplina escolar Ciências. Nesse sentido, a ecologia como enfoque curricular é uma inovação que é sustentada pela (e, ao mesmo tempo, ajuda a sustentar a) estabilidade curricular da disciplina escolar Ciências.

No que se refere aos livros de Paulo Maurício Silva e Sebastião Rodrigues Fontinha Filho, tal inovação já pode ser percebida em duas versões do primeiro volume da coleção 'Ciências no $1^{\circ}$ Grau', ambas publicadas durante a década de 1970 (GOMES, 2008). Essas versões, destinadas ao ensino da disciplina escolar Ciências na antiga quinta série do Ensino Fundamental, revelam enfoques organizadores do currículo e finalidades de ensino em processo de mudança, introduzindo e trazendo para a disputa os conhecimentos ecológicos. Em outras palavras, podemos dizer que as duas versões da referida coleção apresentam semelhanças e diferenças que podem ser interpretadas como sinais de propostas cujos enfoques curriculares estão em processo de transformação. Nesse contexto, argumentamos que a principal mudança evidenciada diz respeito à opção dos autores por um enfoque ecológico, sendo este representado tanto por conteúdos e por propostas metodológicas inovadoras quanto por mudanças, por exemplo, na própria ilustração do volume, que deixa de apresentar uma fotografia microscópica de uma rocha e passa a apresentar uma imagem da Amazônia. Consideramos que todo esse processo constitui uma inovação, inventando uma nova tradição de ensino que não descarta as já existentes no ensino de Ciências, uma vez que veio sendo produzida em meio a processos de estabilidade curricular.

\section{Considerações finais}

Como dissemos anteriormente, buscamos perceber as inovações curriculares produzidas no âmbito da disciplina escolar Ciências em meio ao momento político do 'movimento renovador' desse ensino e, mais especificamente, em duas versões de uma coleção de livros didáticos publicadas na década de 1970. Afinal, o 'movimento de renovação do ensino de Ciências' ocorrido no bloco capitalista chega ao Brasil em meio a uma política educacional pós-1964, que se apoia em uma crescente influência estadunidense, a qual se expande por boa parte da América Latina. Nesse contexto, podemos dizer que as 'novidades' são, ao mesmo tempo, 'progressistas' e 'conservadoras', guardando marcas dessa ambivalência na 'invenção' de novas tradições para o ensino da disciplina escolar Ciências que se movimentam em meio a processos de estabilidade curricular.

Compreendendo essas 'inovações' como construções que resultam de tensões entre o tradicional e o 'novo' - ao invés de percebê-las como rupturas 'revolucionárias' -, vimos valorizando o papel das instituições e de seus atores sociais na produção de padrões sociais e de retóricas legitimadoras para o 'bom' ensino de Ciências. Nesse contexto, defendemos que a introdução de conhecimentos ecológicos, nos anos de 1970, na disciplina escolar Ciências, pode ser considerada uma 'inovação' curricular que dialoga com 'tradições' já existentes. As- 
sim, tomando os livros didáticos como materiais curriculares que participam das 'invenções' de tradição, percebemos as coleções de Paulo Maurício Silva e Sebastião Rodrigues Fontinha Filho, publicadas no período, trazendo esses conhecimentos ecológicos em meio às influências sofridas pelos padrões e retóricas hegemônicos na disciplina escolar.

\section{Referências}

BARRA, V. M.; LORENZ, K. M. Produção de materiais didáticos de Ciências no Brasil, período: 1950 a 1980. Ciência e Cultura, São Paulo, v. 38, n. 12, p. 1970-1983, 1986.

BRASIL. Lei 4.024 de 20 de dezembro de 1961. Fixa as diretrizes e bases da educação nacional. In: BRASIL. Ministério da Educação. Documenta. Rio de Janeiro: Gráfica Tupy, 1962.

BRUNER, J. The process of education. New York: Vintage, 1960.

CHASSOT, A. Ensino de ciências no começo da segunda metade do século da tecnologia. In: LOPES, A. C.; MACEDO, E. Currículo de ciências em debate. Campinas: Papirus, 2004. p. 13-44.

CORDEIRO, J. F. P. Falas do novo, figuras de tradição: o novo e o tradicional na educação brasileira (anos 70 e 80). São Paulo: Editora da UNESP, 2002.

DEBOER, G. E. A history of ideas in science education: implications for practice. New York: Teachers College Press, 1991.

FÁVERO, M. L. Acordos MEC-USAID: significado e implicações para a educação superior brasileira. [S. 1.: S. n.], [19-]. Mimeografado.

FERREIRA, M. S. A história da disciplina escolar ciências no Colégio Pedro II (1960-1980). 2005. Tese (Doutorado em Educação) - Faculdade de Educação, Universidade Federal do Rio de Janeiro, Rio de Janeiro, 2005.

. Investigando os rumos da disciplina escolar ciências no Colégio Pedro II (1960-1970).

Educação em Revista, Belo Horizonte, v. 45, p. 127-144, 2007.

GOMES, M. M. Conhecimentos ecológicos em livros didáticos de ciências: aspectos sócio-históricos de sua constituição. 2008. Tese (Doutorado) - Faculdade de Educação, Universidade Federal Fluminense, Niterói, 2008.

GOMES, M. M.; SELLES, S. E.; LOPES, A. C. Estabilidade e mudança curriculares em livros didáticos de ciências. Educação e Pesquisa: revista da Faculdade de Educação da Universidade de São Paulo, São Paulo, v. 39, n. 2, p. 477-492, 2013.

GOODSON, I. F. Currículo: teoria e história. Petrópolis: Vozes, 1995.

. A construção social do currículo. Lisboa: EDUCA, 1997.

HOBSBAWM, E. Introdução: a invenção das tradições. In: HOBSBAWM, E. \& RANGER, T. (orgs.) A invenção das tradições. 3. ed. Rio de Janeiro: Paz e Terra, 2002. p. 09-23.

KRASILCHIK, M. Inovação no ensino das ciências, In: GARCIA, W. E. (Org.). Inovação educacional no Brasil: problemas e perspectivas. 3. ed. São Paulo: Cortez; Campinas: Autores Associados, 1995. p. 177-194. 
LORENZ, K. M. As reformas do ensino das ciências no ensino secundário brasileiro nas décadas de 1960 e 1970. Revista Portuguesa de Pedagogia, Coimbra, v. 39, n. 1, p. 97-112, 2004.

ROMANELLI, O. O. História da educação no Brasil. Petrópolis: Vozes, 2007.

ROQUETTE, D. A. G. Modernização e retórica evolucionista no currículo de Biologia: investigando livros didáticos dos anos de 1960/70. 2011. 79 f. Dissertação (Mestrado) - Faculdade de Educação, Universidade Federal do Rio de Janeiro, Rio de Janeiro, 2011.

RUDOLPH, J. L. Scientists in the classroom: the cold war reconstruction of American science education. New York: Palgrave, 2002.

PSSC in historical context: science, national security, and American culture during the cold war. [S. 1.]: American Association of Physics Teachers, 2006. Disponível em: <http:// www.compadre.org/portal/pssc/docs/Rudolph.pdf>. Acesso em: 09 maio 2014.

SANTOS, E. F.; AZEVEDO, M. L. N. O ensino superior no Brasil e os acordos MEC/USAID: uma contribuição ao estudo do intervencionismo norte-americano na educação brasileira. In: SEMINÁRIO DE PESQUISA DO PROGRAMA DE PÓS-GRADUAÇÃO EM EDUCAÇÃO DA UEM, 2003, Maringá. Anais... PPE/UEM, 2003. p. 1-10.

SCHWAB, J. The teaching of science as inquiry. In: The teaching of science. Cambridge: Harvard University Press, 1962. p. 1-103.

VALLA, D. F. Currículo de ciências (1950/70): influências do professor Ayrton Gonçalves da Silva na comunidade disciplinar e na experimentação didática. 2011. 107 f. Dissertação (Mestrado) - Faculdade de Educação, Universidade Federal do Rio de Janeiro, Rio de Janeiro, 2011.

VALLA, D. F.; FERREIRA, M. S. Currículo de ciências: investigando ações e retóricas do CECIGUA nos anos de 1960/70. In: BORGES, R. M. R.; IMHOFF, A. L.; BARCELLOS, G. B. (Org.). Educação e cultura científica e tecnológica: centros e museus de ciências no Brasil. Porto Alegre: EDIPUCRS, 2012. p. 169-183.

VIEIRA, M. V. A construção do conhecimento na ciência ecologia. In: ENCONTRO REGIONAL DE ENSINO DE BIOLOGIA, 2., 2003, Niteroi. Anais... SBEnBIO, Regional 2003, p. 31-36. 